\title{
O PODER DE INFLUENNCIA DOS ALGORITMOS NO COMPORTAMENTO DOS USUARIOS EM REDES SOCIAIS E APLICATIVOS
}

\section{THE POWER OF INFLUENCE OF ALGORITHMS ON USER BEHAVIOR IN SOCIAL NETWORKS AND APPS}

\section{EL PODER DE INFLUENCIA DE LOS ALGORITMOS EN EL COMPORTAMIENTO DE LOS USUARIOS EN REDES SOCIALES Y APLICATIVOS}

\section{Charles Emmanuel Parchen ${ }^{1}$}

\section{Cinthia Obladen de Almendra Freitas ${ }^{2}$}

Licença CC BY:

Artigo distribuído sob os termos Creative Commons, permite uso e distribuição irrestrita em qualquer meio desde que o autor credite a fonte original.

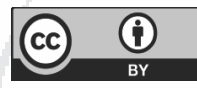

\section{Andreza Cristina Baggio3}

Resumo: O presente artigo visa analisar o comportamento dos usuários da Internet, considerando sua inserção no mundo tecnológico. Aausência de proteção de dados e a mineração destes, a insubsistência da privacidade, hiperexposição de intimidade são efeitos nefastos observados na modernidade, decorrentes do acesso em massa à tecnologia e da busca incessante pela lucratividade. As circunstâncias ora vivenciadas são graves e denota-se que o Direito, dentro de suas limitações burocráticas e deliberativas sequer consegue acompanhar os fatos e as relações que demandam salvaguarda. Desta forma, a presente pesquisa será bibliográfica, de método hipotético-dedutivo, e buscará características das redes e seus principais modelos para permitir a identificação das redes sociais ao respectivo modelo de negócios. No tocante a relação usuário-empresa, será abordada a influência dos algoritmos nas tomadas de decisão dos usuários, para ao final, demonstrar a responsabilidade dos algoritmos nos impulsos de maus comportamentos dos usuários de redes sociais e aplicativos.

1 Doutor em Direito Econômico e Socioambiental pela Pontifícia Universidade Católica do Paraná (PUC/PR). Mestre em Direito Econômico e Socioambiental pela PUCPR. Especialista em Direito Processual Civil pela PUCPR e em Direito Privado pela Universidade Gama Filho-RJ. Advogado. Professor do curso de Direito do Centro Universitário Curitiba (UNICURITIBA), Curitiba-PR, Brasil. Professor do curso de Direito das Faculdades Santa Cruz - CuritibaPR, Brasil. E-mail: charlesadv@gmail.com

2 Doutora em Informática pela PUCPR. Professora Titular da PUCPR da Escola de Direito-Curitiba-Paraná-Brasil. Professora Permanente do Programa de Pós-Graduação Econômico e Socioambiental (Mestrado e Doutorado) da PUCPR- Curitiba-PR, Brasil. E-mail: cinthia@ppgia.pucpr.br

3 Doutora em Direito Econômico e Socioambiental pela Pontifícia Universidade Católica do Paraná (2010), Mestre em Direito Econômico e Social pela Pontifícia Universidade Católica do Paraná (2006), Professora no Curso de Especialização em Direito Processual Civil em EAD UNINTER IBPEX. Associada ao Instituto Brasileiro de Política e Direito do Consumidor - BRASILCON. Curitiba-PR, Brasil. E-mail: baggio.andreza@gmail.com 
Palavras-chave: Algoritmos; Comportamento; Mídias sociais; Aplicativos; Sociedade da informação.

Abstract: This article analyzes the behavior of Internet users, considering their insertion in the technological world. The absence of data protection, data mining, the lack of privacy, and the overexposure of intimacy are the nefarious effects observed in modernity, due to the widespread access to technology and the incessant search for profitability. The circumstances experienced here are serious, and it is denoted that the law, within its bureaucratic and deliberative limitations, is unable to keep abreast of the facts and the relations that require safeguarding. This is bibliographical study, using the deductive-hypothetical method. It searches for characteristics of the networks and their main models that will allow the identification of the social networks to the respective business model. In terms of the user-company relationship, the influence of the algorithms on users' decisionmaking will be addressed, in order to demonstrate the responsibility of the algorithms in the impulses of bad behavior of users of social networks and apps.

Keywords: Algorithms; Behavior; Social medias; Apps; Information society.

Resumen: El presente artículo aspira analizar el comportamiento de los usuarios en la Internet, considerando su inserción en el mundo tecnológico. La ausencia de protección de datos y la explotación de estos, la falta de privacidad, la hiperexposición de intimidad son efectos nefastos observados en la modernidad, decorrentes del acceso en masa a la tecnología y de la busca incesante por el lucro. Las circunstancias ora vivenciadas son graves y denotan que el Derecho, dentro de sus limitaciones burocráticas y deliberativas no consigue acompañar los hechos y las relaciones que demandan salvaguarda. De esta forma, la presente investigación será bibliográfica, de método hipotético deductivo, y buscará características de las redes y sus principales modelos para permitir la identificación de las redes sociales al respectivo modelo de negocios. En relación al usuario empresa, será abordada la influencia de los algoritmos en las tomas de decisión de los usuarios, con el fin, de demostrar la responsabilidad de los algoritmos en los impulsos de malos comportamientos de los usuarios de redes sociales y aplicativos.

Palabras clave: Algoritmos; Comportamiento; Redes sociales; Aplicativos; Sociedad de la información.

\section{INTRODUÇÃO}

O mais recente relatório anual da Pesquisa Nacional por Amostra de Domicílios (PNAD TIC) contínua do IBGE mostra que, para o ano de 2018, 74,9\% dos domicílios brasileiros acessou a Internet (web), sendo que três quartos da população de 181.869 milhões de pessoas com 10 ou mais anos de idade, acessou a Internet. O percentual de jovens entre 18 a 24 anos que utilizaram a rede mundial de computadores foi de $91 \%$. Em relação ao ano anterior, chama a atenção o crescimento do número de idosos (60 anos ou mais): de 31,2\% no ano de 2017, para 36,7\% em 2018. ${ }^{4}$

4 IBGE. Pesquisa nacional por amostra de domicílios - PNAD contínua. Ano 2018. Disponível em: https://ftp. ibge.gov.br/Trabalho_e_Rendimento/Pesquisa_Nacional_por_Amostra_de_Domicilios_continua/Anual/Acesso_ Internet_Televisao_e_Posse_Telefone_Movel_2018/Analise_dos_resultados_TIC_2018.pdf, p. 61-64 Acesso em 10 dez.2020. 
O principal equipamento (hardware) utilizado para o acesso foi o telefone móvel celular, correspondendo a, no ano de 2018, a 98,1\% da população em 10 ou mais anos de idade, sendo que as pessoas também usaram microcomputadores $(50,7 \%)$, televisões (smartv's - 23,1\%) e tablets $(12,0 \%)^{5}$

Estes números ressaltam a importância da Internet, que se expandiu exponencialmente com base no seu uso: de acordo com a necessidade, houve o acréscimo de nós à rede mundial de computadores. E por intermédio dos protocolos padrões criados por Tim Berners-Lee, computadores de todo o Globo, seja de redes locais ou privadas, sejam criando serviços públicos como e-mail, chats e outros, aumentaram a conexão e ao mesmo tempo, a descentralização da rede. ${ }^{6}$

O resultado deste processo é que, se em meados de 1990 havia 25 milhões de usuários com 44 mil redes de computadores conectados, ${ }^{7}$ para o ano de 2019 a Agência para Tecnologias da Informação e Comunicação das Nações Unidas (ITU), noticiou que havia 4 bilhões de usuários ${ }^{8}$.

Por sua vez, estatísticas do portal Internet World Stats informam que 4.9 bilhões de pessoas em todo o globo usavam a rede mundial de computadores até setembro de 2020, sendo que em média, para março do mesmo ano, as taxas de penetração da Internet são de $95 \%$ na América do Norte, $71,8, \%$ na América do Sul e de apenas 39,3\% na África ${ }^{9}$. Dentre as principais razões que podem ser listadas para explicar esta escalada da Internet está o barateamento dos computadores de mesa, a popularização dos smartphones e dispositivos móveis como tablets e notebooks, o surgimento e aplicação massiva da tecnologia da computação em nuvem (Cloud Computing) e também pelo advento e disseminação da denominada "banda larga", ou de alta velocidade.

Os percentuais acima referenciados, relativos à finalidade do acesso da web, levam à uma inevitável curiosidade: porque o uso da Internet está massivamente concentrado em aplicativos de comunicação, logo, de interação? Fato notório é que, dentre os produtos e serviços ofertados, os mais populares constituem-se nas redes sociais, que promovem não só a aproximação e interação imediata dos usuários ${ }^{10}$, mas também proporcionam facilidades e conforto no cotidiano, já que são capazes de prover inúmeros serviços.

5 IBGE. Pesquisa nacional por amostra de domicílios - PNAD contínua. Ano 2018. Disponível em: https://ftp. ibge.gov.br/Trabalho e Rendimento/Pesquisa Nacional por Amostra de Domicilios continua/Anual/Acesso Internet_Televisao_e_Posse_Telefone_Movel_2018/Analise_dos_resultados_TIC_2018.pdf, p. 61-64. Acesso em 10 dez. 2020

6 CASTELLS, Manuel. A galáxia da Internet, reflexões sobre a Internet, os negócios e a sociedade. Zahar, 2003, p.29.

7 CASTELLS, Manuel. A sociedade em rede. A era da informação: economia, sociedade e cultura. v.1.São Paulo: Paz e Terra, 1999, p. 369.

8 UNITED NATIONS. International Telecommunication Union. Internet users statistics by region and country 2005-2019. Disponível em: https://www.itu.int/en/ITU-D/Statistics/Pages/stat/default.aspx. Acesso em 10 dez.2020 INTERNET WORLD STATS. Internet usage statistics. Disponível em: https://www.internetworldstats.com/stats. htm. Acesso em 10 dez.2020.

10 Importa esclarecer ao leitor que o termo usuário será utilizado no presente estudo para designar aquela pessoa natural ou jurídica que utiliza diariamente de serviços e aplicativos baseadas na rede mundial de computadores. 
A importância delas é corroborada em números. A título de exemplo, tem-se o Snapchat: com mais de 1 bilhão de downloads, ${ }^{11}$ foi criado nos Estados Unidos no ano de $2011^{12}$ e tem mais de 249 milhões de usuários diários ativos. ${ }^{13}$ Já o Facebook, maior rede social conhecida atualmente, teve o início de suas atividades no ano de 2004 e possui, no ano de 2020, 2.7 bilhões de usuários. ${ }^{14}$ Uma simples consulta à PlayStore demonstra que a aplicação da mencionada rede social para smartphones tem mais de cinco bilhões de downloads. ${ }^{15}$ Por sua vez, a rede social WhatsApp existe desde o ano de $2009{ }^{16}$ e tinha mais de 1,5 bilhão de usuários ativos para o ano de $2018 .^{17}$

Ocorre que toda esta gama enorme de pessoas usando ao mesmo tempo um mesmo produto ou serviço vai gerar evidentes e graves problemas de ordem socioambiental: é proposição do presente estudo afirmar que o "choque", "colisão" ou "fricção" é inevitável porque, como melhor se verá no capítulo adequado, não só as características naturais de uma rede levam à inevitáveis litígios, mas também usuário, de uma maneira em geral, não sabe se comportar em redes sociais.

Ao mesmo tempo, as empresas que operam redes sociais são altamente experenciadas e eficazes quando o assunto é o comportamento humano. Isto ocorre basicamente porque, conforme melhor se demonstrará ao longo do estudo, elas guardam estrita e grande dependência em relação à forma pela qual o usuário age e se comporta: ela é o sustentáculo do seu sistema lucrativo, todo baseado na mineração de dados (Data Mining).

Assim, Facebook, Instagram, WhatsApp e outras contam, dentre seus departamentos, com equipes altamente especializadas no estudo do comportamento (behaviorismo), de técnicas de marketing e, portanto, sabem como influenciar o processo de tomada de decisão de seus usuários.

Desta forma, geram-se consequências nefastas, tais como perda da privacidade e intimidade, furto de dados bancários, golpes eletrônicos e crimes virtuais e reais baseados em fatos de Internet (apenas para citar alguns exemplos) são especialmente superlativados, promovidos e incentivados por conta da forma pela qual as empresas que operam as redes sociais atuam: os seus algoritmos são propositalmente elaborados para influenciar uma produção incessante de dados, corroborando maus comportamentos.

11 PLAYSTORE. Disponível em: https://play.google.com/store. Acesso em 10 dez. 2020.

12 JORNAL THE TELEGRAPH. Who owns Snapchat and when was it created?. Disponível em: https://www. telegraph.co.uk/technology/0/owns-snapchat-created/. Acesso em 02 jun. 2019. p. 01.

13 PORTAL STATISTA. Disponível em: https://www.statista.com/statistics/545967/snapchat-app-dau/. Acesso em 10 dez. 2020.

14 PORTAL STATISTA. Disponível em: https://www.statista.com/statistics/264810/number-of-monthly-activefacebook-users-worldwide/\#: :text=How\%20many\%20users\%20does\%20Facebook, the \%20biggest $\% 20$ social\%20network\%20worldwide. Acesso em 10 dez. 2020.

15 PLAYSTORE. Disponível em: https://play.google.com/store. Acesso em 10 dez. 2020.

16 ÂNGELO, Kedson. A história da criação do WhatsApp. Disponível em: https://www.linkedin.com/pulse/ hist\%C3\%B3ria-da-cria\%C3\%A7\%C3\%A3o-do-whatsapp-kedson-angelo. Acesso em 10 dez. 2020.

17 PORTAL TECHTUDO. WhatsApp bate marca de 1,5 bilhão de usuários ativos. Disponível em: https://www. techtudo.com.br/noticias/2018/02/whatsapp-bate-15-bilhao-de-usuarios-ativos.ghtml. Acesso em 10 dez. 2020. 
Na medida em que se aproveitam de esquemas mentais psicológicos dos usuários, as redes sociais influenciam por intermédio de "cutucões e empurradas" - nudges ${ }^{18}$ - o processo de tomada de decisão em torno da potencialização da consecução de seus objetivos: lucrar cada vez mais com a mineração e a venda dos dados sensíveis e pessoais dos usuários, expondo-os à toda gama de consequências ruins que estes suportam com exclusividade. A hipótese a ser testada, portanto, no presente estudo é a de que as redes sociais, por seus algoritmos, influenciam e são responsáveis pelos maus comportamentos dos usuários. A importância do tema advém do fato de que se maus comportamentos ocorrem principalmente porque as empresas adotam de forma propositada e egoística, logo e em detrimento dos direitos elementares do usuário, uma postura claramente utilitarista ${ }^{19}$ - urge a inexorável necessidade de intervenção, análise e atuação do Direito enquanto ciência e saber jurídico, para que se possa proporcionar reflexões e tentar se cunhar soluções práticas adequadas aos contemporâneos obstáculos ao desenvolvimento sustentável que são criados e se apresentam.

O cenário que se apresenta é especialmente dramático, porque o Direito, enquanto norma de conduta e regramento, não consegue dar uma resposta eficaz, na medida em que não acompanha a contento, a velocidade da demanda da sociedade, do surgimento de novas tecnologias e suas transformações. Desta forma, o usuário encontra-se hipervulnerável.

Governos e Nações já se atentaram ao problema: recentes normativas, tais como a Lei 12.965/2014 - Marco Civil da Internet - e mais veementemente com a promulgação em 14 de agosto de 2018 da lei 13.709/2018 - Lei de proteção de dados ${ }^{20}$ e a denominada GDPR (General Data Protection Regulation) que entrou em vigor em maio do ano de 2018 (GDPR.ORG, 2018.p.1) na União Europeia são tentativas pioneiras e corajosas de promover os direitos e garantias individuais fundamentais. Elas vão trazer, por exemplo, dentre os seus princípios explícitos, a garantia da autodeterminação informativa (art. $1^{\circ}$, parágrafo II) o do livre desenvolvimento da personalidade da pessoa natural (art. $1^{\circ}$, caput) e o da proibição do tratamento de dados mediante vício do consentimento (art. $8^{\circ}$, parágrafo $3^{\circ}$ ). ${ }^{21}$

Para tanto, usando do método hipotético-dedutivo e da revisão bibliográfica, traz à discussão as características de redes e seus principais modelos, com o escopo de permitir a perfeita identificação das redes sociais a um deles. Ainda, no contexto das redes sociais e da sociedade de algoritmos, aborda a relação usuário-empresa e o poder de influência dos algoritmos no processo de tomada de decisão. Ao final, conclui pela existência de responsabilidade decisiva dos algoritmos em corroborar e incentivar comportamentos dos usuários de redes sociais e aplicativos.

$18 \quad$ Nudges podem ser entendidos como processos indutivos de escolhas, elaboradas com o intuito de que outras pessoas façam sua adesão a elas. Para maior informação, vide: SUNSTEIN, Cass. THALER, Richard. Nudge: como tomar melhores decisões sobre saúde, dinheiro e felicidade. Rio de Janeiro: Editora Objetiva, 2019. Versão do Kindle.

19 Entendido aqui como o "princípio da maior felicidade", de Jeremy Bentham.

20 BRASIL. [Lei 13.708 (2018)]. Lei de proteção de dados. Brasília, DF: Presidência da República [2018]. Disponível em: http://www.planalto.gov.br/ccivil_03/_Ato2015-2018/2018/Lei/L13709.htm. Acesso em 10 dez. 2020.

21 BRASIL. [Lei 13.708 (2018)]. Lei de proteção de dados. Brasília, DF: Presidência da República [2018]. Disponível em: http://www.planalto.gov.br/ccivil_03/_Ato2015-2018/2018/Lei/L13709.htm. Acesso em 10 dez. 2020. 


\section{DA MATEMÁTICA ÀS REDES SOCIAIS}

Para se chegar às redes sociais, é necessário antes compreender que o conceito de redes não é proveniente do campo da Informática, mas sim da ciência da Matemática. O estudo de redes surgiu muito tempo antes do advento do computador. Neste sentido é importante mencionar as análises pioneiras do matemático suíço Leonhard Euler, trazidas por Albert Barabasi em sua obra denominada Linked: a nova ciência dos networks.

As contribuições e descobertas de Euler, desde o ano de 1783 e para o campo da astronomia e física (tais como o comportamento de balões em voo) são notórios e consagrados. Mas Barabasi chama a atenção para um curto artigo de Euler que destacava um problema originado na cidade de Konigsberg-Prússia e próxima de São Petersburgo, onde este morava.

Segundo a narrativa, a cidade prussiana era pujante e enriqueceu com o comércio de trocas baseado em navios mercantes. ${ }^{22}$ Os funcionários da cidade resolveram construir, então, sete pontes sobre o rio Pregel, ligando a ilha de Kneiphof, que era separada por dois braços do rio, com as demais partes da cidade.

Segundo Barabasi, ${ }^{23}$ a população local, vivendo tempos de paz e prosperidade, passava então o seu tempo lançando desafios ou puzzles. Um destes passou a envolver as sete pontes, onde era necessário desvendar a seguinte problemática: "pode-se cruzar as sete pontes sem jamais passar pela mesma ponte duas vezes?". 24

No ano de 1736, Euler elaborou uma solução científica para a questão, provando que tal indagação proposta pelo desafio das sete pontes era impossível de ser realizada na prática. Com isto, ele inaugurou o que na matemática convencionou-se chamar de Teoria do Grafo (graph theory), que, segundo Barabasi, é a base de maior contribuição para se pensar atualmente sobre redes e seu funcionamento. ${ }^{25}$

O matemático suíço vislumbrou nas pontes de Konigsberg, coleções de nós conectados por retas (arestas ou links). A representação destas conexões é o grafo. Assim, utilizou os nós para representar cada uma das quatro áreas separadas pelo rio Pregel, as quais foram distintas e representadas pelas letras maiúsculas A, B, C e D. As pontes (representadas como sendo links), foram designadas por letras minúsculas. Desta forma, formado estava o grafo com quatro nós e sete arestas.

O matemático provou que o desafio das sete pontes era uma falácia, sendo impossível de ser resolvido sem que houvesse uma reestrutura da topologia da rede que havia sido criada com as conexões providas pela ponte. ${ }^{26}$

22 BARABASI, Albert-Lászlo. Linked: a nova ciência dos networks. São Paulo: Leopardo Editora, 2009, p. 09.

23 BARABASI, Albert-Lászlo. Linked: a nova ciência dos networks. p. 09.

24 BARABASI, Albert-Lászlo. Linked: a nova ciência dos networks. p. 09.

25 BARABASI, Albert-Lászlo. Linked: a nova ciência dos networks. p. 10.

26 BARABASI, Albert-Lászlo. Linked: a nova ciência dos networks. p. 11. 
Com isto, a cidade de Konigsberg foi compelida a, no ano de 1875, construir uma nova ponte entre os nós $B$ e $C$, deixando apenas os nós $A$ e $D$ com número ímpar de ligações. ${ }^{27}$ Ademais, a conclusão do estudo de Euler foi dada por Barabasi: ${ }^{28}$

Para nosso propósito, o aspecto mais importante da prova de Euler é que a existência do caminho não depende de nossa ingenuidade para encontrálo. Trata-se, mais exatamente, de uma propriedade do grafo. Dado o layout das pontes de Konigsberg, independentemente de nossa perspicácia, jamais conseguiremos encontrar o caminho desejado[...]. Em retrospectiva, a mensagem involuntária de Euler é muito simples: grafos ou redes possuem propriedades, ocultas em sua construção, que limitam ou intensificam nossa capacidade de lidar com eles.

Denota-se, pelo apontamento do matemático suíço, que a forma (layout) de construção das ligações fez a rede seguir seu próprio e natural fluxo e, desta forma, impossibilitando que o agir humano (por mais expert que seja) tivesse como encontrar o caminho desenhado em tese pelo problema matemático proposto.

Esta caracterização de redes acaba evidenciando que elas são estáticas ou rígidas, ou seja, que não apresentam caráter dinâmico, mas dependem de um caminho formado naturalmente, mas ao mesmo tempo dependente da forma pela qual a rede foi construída.

Somente a mudança de configuração (layout) das arestas - o que ocorreu somente com a adição de mais uma ponte - é que possibilitou aos moradores de Konigsberg a solução de parcela importante de suas limitações diárias de tráfego entre as localidades (ou nós) da cidade, ou aos dizeres de Barabasi, "Pequenas mudanças na topologia, afetando tão somente alguns poucos nós ou links, podem abrir portas ocultas, permitindo a emergência de novas possibilidades"29. Deste modo, a matemática se une à atualidade, fazendo-se necessária uma reflexão pautada nas redes sociais.

\subsection{REDES SOCIAIS}

A teoria dos grafos (como ficou conhecida a obra de Euler) tem intima ligação com o estudo das redes computacionais, permitindo a compreensão e análise destas até os dias atuais. A importância do estratagema do referido matemático em relação às redes deriva da analogia e subsunção de que, nestas, os usuários são os nós e as arestas, as ligações geradas pela dinamicidade das interações entre eles.

Outra conclusão a que se pode chegar, a partir da informação de Barabasi, é a de que fica provado que conexões (links) são o substantivo da rede; logo, ambos são indissociáveis e interdependentes.

27 BARABASI, Albert-Lászlo. Linked: a nova ciência dos networks. p. 11.

28 BARABASI, Albert-Lászlo. Linked: a nova ciência dos networks. p. 11.

29 BARABASI, Albert-Lászlo. Linked: a nova ciência dos networks. p. 11. 
E é especialmente notável na obra de Manuel Castells, que assevera que ela é a base de tecnologia para a "forma organizacional era da informação: a rede". ${ }^{30}$ Neste sentido, Raquel Recuero diz que o local onde as conexões ocorrem é o que se pode designar como sendo a efetiva rede de relacionamentos sociais no ambiente virtual. Esta afirmação permite compreender o fato de que a Internet é locus por excelência, de relações sociais: sem ela, as interações Humanas digitais imediatas e instantâneas seriam impossíveis. ${ }^{31}$

É importante afirmar ao leitor que a clássica conformação de redes em grafos não serve a explicar as redes sociais contemporâneas, pois aqueles possuem layout fixo e dependem de uma alteração em sua estrutura para aumentar o número de ligações. Ademais, denota-se que o caminho ou percurso entre elas é completamente alheio à expertise humana: a forma como grafo é construído determina um fluxo natural de ligações que a vontade Humana não consegue modificar com facilidade.

Logo, as redes sociais constituem o oposto da teoria clássica dos grafos. Isso porque elas devem ser compreendidas não como estruturas determinadas e determinantes, mas sim como "mutantes no tempo e espaço". ${ }^{32}$ Elas podem, portanto, ser caracterizadas por sua velocidade e instantaneidade.

Mas também, e essencialmente, pela dinamicidade e indeterminação das relações, na medida em que só podem ser pensadas modernamente dentro de uma perspectiva "ativa" de seus participantes, que acabam dando mutabilidade no tempo e no espaço a tal ambiente, que evolui sempre. ${ }^{33}$

Como dito anteriormente, uma mudança de disposição das ligações, ainda que mínima, é o suficiente para que novas possibilidades de conexão surjam e se ampliem de forma natural, fluida e intrínseca. Por esta razão, é que diversos estudos derivaram da teoria clássica para tentar explicar as redes sociais. Para Barabasi ${ }^{34}$, estes tipos de redes tem natureza "altamente interconectada", que são formadas por uma imensidão de links que, à medida em que são adicionados aos nós (arestas) aumentam cada vez mais a rede mas, ao mesmo tempo, diminuem as distância entre eles: se está diante do que o citado autor chamou de "rede de mundos pequenos", ou seja, redes em que o grau de conexão depende essencialmente das relações entre os usuários conectados e não da distância entre elas. ${ }^{35}$ Afinal, não importa o tamanho e extensão da Internet: todos os documentos e todas as pessoas que estão conectadas à rede mundial de computadores estão interligadas a, mais ou menos, poucos cliques de distância.

30 CASTELLS, Manuel. A galáxia da Internet, reflexões sobre a Internet, os negócios e a sociedade. p. 07.

31 RECUERO, Raquel da Cunha. Redes sociais na internet: considerações iniciais. Porto Alegre: Editora Compós, v. 2, 2005. Disponível em: http://www.ufrgs.br/limc/PDFs/redes_sociais.pdf. Acesso em 10 dez. 2020.

32 RECUERO, Raquel da Cunha. Redes sociais na internet: considerações iniciais. Porto Alegre: Editora Compós, v. 2, 2005. Disponível em: http://www.ufrgs.br/limc/PDFs/redes_sociais.pdf. Acesso em 10 dez. 2020.

33 RECUERO, Raquel da Cunha. Redes sociais na internet: considerações iniciais

34 BARABASI, Albert-Lászlo. Linked: a nova ciência dos networks. p. 30.

35 BARABASI, Albert-Lászlo. Linked: a nova ciência dos networks. p. 36. 
Eé neste contexto de intensiva e massiva conexão, onde os dados são produzidos em gigantescas quantidades, necessitando, portanto, serem filtrados, segmentados, catalogados e separados. Esta demanda advinda do chamado Big Data, portanto, é o que sustenta o modelo de negócios das redes sociais, pois é da venda das informações obtidas por intermédio dos dados dos usuários que elas encontram sua razão lucrativa.

Assim, e principalmente porque contemporaneamente as redes sociais se constituem em locus completamente disseminados na Sociedade Global, as plataformas são dinâmicas, complexas, altamente interativas e que tem a capacidade de mudar constante e rapidamente para se adaptar aos anseios e necessidades de seus usuários, que alimentam diariamente, com seus dados sensíveis e privados, enormes bancos de dados.

Estes, por sua vez, precisam ser tratados, pois diante do volume, velocidade e variedade dos dados, muitos são úteis (e, portanto, podem ser comercializados) e outros não tem qualquer serventia, podendo ser descartados.

É no processo técnico de tratamento destes dados que os algoritmos informáticos incidem, não só para corroborar o modelo de negócios que sustenta as redes sociais - a mineração de dados (Data Mining) - mas também para influenciar bons e maus comportamentos, pois servirão de incentivo e manterão o usuário ativo, dependente e fidelizado à referida tecnologia. Cabe agora, portanto, adentrar à questão dos algoritmos.

\section{SOMOS INFLUENCIADOS POR ALGORITMOS?}

Primeiramente, é possível asseverar que a sociedade global sempre viveu em formato de algoritmos. Esta ideia deriva do que comumente se entende como sendo um algoritmo: "um conjunto de etapas para executar uma tarefa". ${ }^{36}$ Desde a programação da hora de acordar, a escolha de qual roupa usar e a ordem em que ela é vestida (por exemplo, se primeiro a calça e depois a camiseta), o escovar dos dentes, o abrir e fechar de uma torneira, a ordem em que o café com o leite é colocado na xícara (por exemplo, se primeiro o leite e depois o café), a escolha do ônibus que se pega para ir ao trabalho, o trajeto pensado para se deslocar de carro à escola, enfim, o cotidiano e a rotina só se fazem possíveis diante da adoção de etapas logicamente encadeadas que servem ao atingimento de um ou mais objetivos traçados pelo próprio indivíduo em sua liberdade de agir, pensar e se manifestar, ou seja, dentro do seu processo pleno de tomada de decisão.

Esta noção de tomada de decisão visando o estabelecimento de rotinas e etapas necessárias à consecução de um objetivo, embora não seja nova, é amplamente usada quando o assunto é a contemporaneidade e a tecnologia. Isto se deve ao fato de que computadores são capazes de trabalhar com algoritmos em escala infindável e de forma automática, visando a realização de diversas e simultâneas tarefas com a tomada de decisão (reação) em frações de segundo. ${ }^{37}$

36 CORMEN, Thomas H. Desmistificando algoritmos. $1^{\text {a }}$ ed. Rio de Janeiro: Elsevier, 2014, p. 13.

37 PIERRO, Bruno de. O Mundo mediado por algoritmos. São Paulo: Revista Pesquisa Fapesp. ed. 266, abr. 2018. Disponível em: http://revistapesquisa.fapesp.br/2018/04/19/o-mundo-mediado-por-algoritmos/. Acesso em 10 dez. 2020. 
O intuito dos algoritmos é claro: prover por cálculos matemáticos, raciocínio lógico e programação informática, a resolução de diversos problemas humanos em curto espaço de tempo. ${ }^{38}$ Desta forma, tem o condão de substituir o Humano na realização das tarefas, já que executam as mesmas com um grau de eficiência e rapidez muito maior, e a um evidente baixo custo.

Assim, uma das consequências naturais dos algoritmos é que eles acabam servindo a possibilitar ao usuário o gerenciamento mais amplo e confortável do seu tempo (que antes era gasto na consecução de tarefas repetitivas e demoradas), e que passa a ser usufruído em maior liberdade e quantidade; ou seja: é proposição do presente estudo afirmar que a escalabilidade do tempo livre do usuário é a tônica das referidas programações computacionais encadeadas.

Compreende-se, desta forma, a ideia de que algoritmos, quando subsumidos à sociedade tecnológica, faz com que esta se transforme e ganhe contornos ainda mais notáveis e relevantes: é que atualmente se vive a sociedade dos algoritmos, pois estes permeiam por completo a vida humana, onde a incidência dos encadeamentos computacionais é inexorável: as etapas lógicas computacionais estão presentes, em elevado grau, em todas os meandros da vida moderna, seja em um supermercado, na farmácia, no relacionamento com o Governo, na rede social ou em um automóvel, apenas para citar alguns exemplos.

A sociedade global, portanto, desenvolveu um grande grau de dependência dos algoritmos, não podendo mais prescindir dos mesmos no atual patamar tecnológico em que se encontra. Para se reforçar a importância dos algoritmos para a modernidade, é interessante trazer ao conhecimento do leitor os dados postos por Klaus Schwab, Diretor do Fórum Econômico Mundial, em seu livro "A Quarta Revolução Industrial". ${ }^{39}$

Nesta obra, o autor chama a atenção para 23 mudanças (pontos de inflexão) que ele cunhou, a partir de dados coletados por intermédio de uma entrevista com 800 executivos globais, por conta do uso de algoritmos (ou nos dizeres da obra, inteligência artificial). Uma das inflexões teve como resposta positiva de $84 \%$ dos entrevistados, afirmando que até o ano de $2025,80 \%$ das pessoas ao redor do mundo terão presença digital na Internet. ${ }^{40}$

Já para 91\% dos entrevistados, até o ano de 2025, 10\% das pessoas no mundo terão roupas conectadas na rede mundial de computadores. ${ }^{41}$ Por sua vez, para $83 \%$ dos que responderam à pesquisa, até o ano de 2025 haverá o primeiro governo a substituir completamente o censo por analise de Big Data. ${ }^{42}$

38 ABREU, Moises. Qual a importância de algoritmos na programação? Portal Acadtec. Disponível em: https:// www.acadtec.com.br/blog/desenvolvimento-backend/qual-a-importancia-de-algoritmos-na-programacao. Acesso em 10 dez. 2020.

39 SCHWAB, Klaus. A quarta revolução industrial. São Paulo: Edipro, 2016. p.117.

40 SCHWAB, Klaus. A quarta revolução industrial. p. 117.

41 SCHWAB, Klaus. A quarta revolução industrial. São Paulo: Edipro, 2016. p. 121.

42 SCHWAB, Klaus. A quarta revolução industrial. p. 136. 
Neste sentido, também pode-se citar o estudo do Instituto de Pesquisa Econômica Aplicada (IPEA) que apontou que o Brasil, em dezembro de 2016 alcançou o patamar de 40\% das operações da Bovespa feitas por "robôs investidores", ou mecanismos de negociação automatizada (algorithmic trading - AT), passando de $20 \%$ o volume médio diário negociado pelas chamadas transações de alta frequência (High-frequency trading - HFT), usadas para economizar de 2 a 3 milisegundos por transação. ${ }^{43}$ Mas se de um lado algoritmos representam tantos benefícios à sociedade tecnológica, eles também possuem (por causa de suas características) o condão de causar efeitos ou consequências nefastas. À título de exemplo desta afirmação, há estudos que tecem críticas ao uso crescente dos algoritmos em todos os aspectos da vida em sociedade.

Neste sentido, pode-se citar reportagem do jornal The Guardian ${ }^{44}$ que, comentando o uso do algoritmo "Blue Crush" pela Polícia de Memphis, Tennessee, nos Estados Unidos, afirmou:

"It's putting the right people in the right places on the right day at the right time," said Dr Richard Janikowski, an associate professor in the department of criminology and criminal justice at the University of Memphis, when the scheme launched. But not everyone is comfortable with the idea. Some critics have dubbed it "Minority Report" policing, in reference to the sci-fi film in which psychics are used to guide a "PreCrime" police unit. The use of algorithms in policing is one example of their increasing influence on our lives. And, as their ubiquity spreads, so too does the debate around whether we should allow ourselves to become so reliant on them - and who, if anyone, is policing their use. Such concerns were sharpened further by the continuing revelations about how the US National Security Agency (NSA) has been using algorithms to help it interpret the colossal amounts of data it has collected from its covert dragnet of international telecommunications ${ }^{45}$.

O algoritmo que a polícia daquele local usou tem funcionamento simples: com base em técnicas de predição e de interpolação de dados, tais como estatísticas de crimes e locais onde ocorreram, a programação automatizada é capaz de identificar os pontos da cidade ondem mais ocorrem ilícitos. Desta forma, faz com que cresça de forma exponencial, as patrulhas e rondas nos respectivos lugares, resultando em um aumento considerável do número de prisões e encarceramentos, muitos injustos ou

43 SANTANA JUNIOR, Edemilson Cruz. A digitalização do mercado de capitais no Brasil: tendências recentes. Instituto de Pesquisa Econômica Aplicada. Brasília: Rio de Janeiro, 2018. Disponível em: http://repositorio.ipea. gov.br/bitstream/11058/8280/1/TD_2370.PDF. Acesso em 10 dez. 2020

44 THE GUARDIAN. How algorithms rule the world. Disponível em: https://www.theguardian.com/science/2013/ jul/01/how-algorithms-rule-world-nsa. Acesso em: Acesso em 10 dez. 2020.

45 Tradução livre: "É colocar as pessoas certas nos lugares certos, no dia certo, na hora certa", disse Richard Janikowski, professor associado do departamento de criminologia e justiça criminal da Universidade de Memphis, quando o esquema foi lançado. Mas nem todo mundo está confortável com a ideia. Alguns críticos apelidaram o policiamento de "Minority Report", em referência ao filme de ficção científica em que médiuns são usados para guiar uma unidade policial "pré-crime". O uso de algoritmos no policiamento é um exemplo de sua crescente influência em nossas vidas. $E$, à medida que sua onipresença se espalha, o mesmo acontece com o debate em torno de se devemos nos permitir depender tanto deles - e quem, se alguém, está policiando seu uso. Tais preocupações foram aguçadas ainda mais pelas revelações contínuas sobre como a Agência de Segurança Nacional dos EUA (NSA) tem usado algoritmos para ajudar a interpretar as quantidades colossais de dados que coletou de sua rede secreta de telecomunicações internacionais. 
abusivos $^{46}$. O aumento exponencial do uso de algoritmos e as dúvidas que os cercam foi externado pelo Tribunal de Contas da União:

Uma questão relevante, porém, ambígua, sobre o uso de algoritmos refere-se à transparência. Se, por um lado, é possível haver aumento da transparência pelo uso de algoritmos, visto ser possível publicar o seu código e dados, exibindo toda a sua lógica de decisão para que seja avaliada por qualquer um, por outro lado, também é possível utilizar algoritmos como uma "caixa preta", que produz resultados e decisões, mas não permite acesso à sua lógica interna que explicitaria como se chegou à decisão. Nesse último caso, são trazidos argumentos de sigilo das informações utilizadas, licenças comerciais que impossibilitam o acesso ao código ou riscos de prejuízo à ação estatal ou à imagem de seus órgãos caso as razões subjacentes às decisões fossem explicitadas. Outro potencial problema está ligado ao fado de o algoritmo, que pode resultar de um processo de aprendizagem automática com base no histórico de decisões passadas, ser incompreensível, ainda que seja funcional. Ou seja, na tentativa de generalizar decisões passadas o algoritmo resultante pode se tornar excessivamente complexo, não se prestando mais a uma compreensão por meio de regras lógicas simples. Nesse caso, o algoritmo só poderá ser verificado pelos resultados que gera, se for testado de forma sistemática, submetendo-lhe dados que repliquem diversas circunstâncias relevantes ${ }^{47}$.

Já quando o assunto é o mercado de ações, outra crítica diz respeito à perda da chance igualitária de participação entre os diversos tipos de players, já que os "robôs" desequilibrariam as situações e cenários de competição, privilegiando os mais arrojados ou endinheirados (os chamados heavy players), possibilitando ainda a manipulação ilegal e artificial das negociações com o intuito de maximizar os lucros e prejudicar os concorrentes. ${ }^{48}$

Por sua vez, a preocupação com a questão do trabalho e emprego é uma tônica constante de Klaus Schwab ${ }^{49}$, pois ele assevera a possibilidade de aumento do desemprego e até mesmo em extinção de inúmeras posições tradicionais de trabalho. O citado autor compila, em sua já referida obra, um estudo conduzido pela Universidade de Oxford no ano de 2013, que exemplificou as profissões mais e menos propensas à automação completa, logo, à substituição do Humano pelo Computador.

Destaca-se dentre as que mais tendem à automação, as de operador de telemarketing, contadores, avaliadores de riscos (seguros) em danos automobilísticos e corretores de imóveis. Dentre os que menos tendem a desaparecer, estão as profissões de assistentes sociais, coreógrafos e

46 THE GUARDIAN. How algorithms rule the world. Disponível em: https://www.theguardian.com/science/2013/ jul/01/how-algorithms-rule-world-nsa. Acesso em: 10 dez. 2020.

47 SANTOS, Erick Muzart Fonseca dos. A revolução dos algoritmos. Portal Inova TCU. Disponível em: https:// portal.tcu.gov.br/inovatcu/noticias/a-revolucao-dos-algoritmos.htm. Acesso em 10 dez. 2020.

48 SANTANA JUNIOR, Edemilson Cruz. A digitalização do mercado de capitais no Brasil: tendências recentes. Instituto de Pesquisa Econômica Aplicada. Brasília: Rio de Janeiro, 2018. Disponível em: http://repositorio.ipea. gov.br/bitstream/11058/8280/1/TD_2370.PDF. Acesso em 10 dez. 2020.

49 SCHWAB, Klaus. A quarta revolução industrial. São Paulo: Edipro, 2016, p. 44. 
psicólogos. ${ }^{50} \mathrm{~A}$ razão aparente destas mencionadas profissões estarem entre as que menos tendem a serem automatizadas deriva do fato de que elas dependem e grande parte da inventividade e criatividade humana, ou seja, do pouco encadeamento lógico e sistemático. Com efeito, é proposição deste artigo afirmar que ocupações de ordem eminentemente criativa possuem elevado grau de serendipidade, característica esta que o algoritmo não consegue ter ou lidar.

Desde já é possível então saber que uma característica dos algoritmos advém do fato de que, ao contrário do Humano, aqueles são nada criativos ou inventivos, pois depende exclusivamente de repetição, encadeamento, lógica e, claro, predição e programação. Desta forma, profissões decorrentes de um baixo grau de instrução (repetitivas, mecânicas ou burocráticas) ou que façam mão de cálculos são as que mais tendem à mencionada substituição.

Importa ressaltar ao leitor que embora estas citadas consequências negativas e afetas aos algoritmos sejam importantes, elas não compõem o escopo de análise do presente estudo e, portanto, não merecerão análise aprofundada. O que importa para o artigo é esclarecer ao leitor que, com o uso massivo e tecnológico dos algoritmos na sociedade, há a ocorrência de uma clara ruptura no processo de tomada de decisão: os algoritmos, uma vez que possuem o condão de substituir o Humano em suas diversas tarefas cotidianas, acaba por transmutar a vontade deste, suprimindo o processo de livre tomada de decisão e escolha proveniente de todo e qualquer pensar e agir que seja racional, consentido e principalmente ponderado.

Esta questão da substituição da tomada de decisão Humana pelo algoritmo fica bastante evidenciada na obra Homo Deus, de Yuval Harari:

Se no século XXI as estruturas políticas tradicionais não mais processarem os dados com a rapidez necessária para suscitar visões significativas, então estruturas novas e mais eficientes vão se desenvolver para assumir seu lugar. Essas novas estruturas poderão ser muito diferentes de quaisquer instituições políticas anteriores, tanto democráticas quanto autoritárias. A única questão é quem vai construir e controlá-las. Se o gênero humano não estiver à altura da tarefa, talvez devesse deixar essa tentativa para outrem ${ }^{51}$.

E é a partir desta noção que o referido sociólogo cunha a ideia do chamado dataísmo ${ }^{52}$ : uma autêntica religião que, com base técnico-científica, transforma o Universo em um "fluxo de dados", sendo que "o valor de qualquer fenômeno ou entidade é determinado por sua contribuição ao processamento de dados" 53 .

50 SCHWAB, Klaus. A quarta revolução industrial. São Paulo: Edipro, 2016, p. 45.

51 HARARI, Yuval Noah. Homo Deus: uma breve história do amanhã. 1a ed. São Paulo: Companhia das Letras, 2016, p. 380.

52 O termo dataísmo (dataism) deriva do termo data, em inglês e é cunhado pelo citado autor em forma de neologismo. Trata de designar um movimento cultural de veneração aos dados, que passou a ser o centro da nova economia global, baseada na compra e venda de dados informáticos.

53 HARARI, Yuval Noah. Homo Deus: uma breve história do amanhã. p.370. 
O dataísmo, portanto, caracteriza-se pela união entre os algoritmos bioquímicos e os eletrônicos, fazendo "ruir a barreira que separa os animais e máquinas" e com "a expectativa de que, eventualmente, os algoritmos eletrônicos decifrem e superem os algoritmos bioquímicos" 54 .

Neste novo tipo de crença, os algoritmos eletrônicos têm grande papel de destaque, na medida em que nada mais são do que processos encadeados que visam uma tomada de decisão mais rápida e eficiente em face da capacidade cognitiva humana, que é limitada, especialmente diante da complexidade e do infindável número de escolhas disponíveis. Como consequência, influenciando decisivamente sobre o comportamento, terão os algoritmos informáticos a potencialidade de interferir de maneira cabal no objetivo final almejado pelo usuário, sujeitando este a riscos desnecessários e muitas vezes a consequências nefastas e não desejadas.

E a forma encontrada pelo Mercado ou Governos em usar algoritmos se dá pelos instrumentos contratuais de produtos e serviços tecnológicos (termos de uso e serviço). Nestes, (negócios jurídicos que são) constam cláusulas onde se impõe ao usuário - ao qual só cabe aderir aos termos - a concessão de diversas autorizações para o fornecedor poder utilizar de algoritmos. A justificativa geralmente advém do fato de que o uso da linguagem de programação encadeada e lógica serve a facilitar a experiência e tornar a fruição do produto ou serviço, mais confortável ao usuário.

É o que se observa, por exemplo, dos Termos de Uso e Serviço do Facebook ${ }^{55}$ :

Sua experiência no Facebook não se compara à de mais ninguém - desde publicações, histórias, eventos, anúncios e outro conteúdo que você vê no Feed de Notícias ou em nossa plataforma de vídeo até as Páginas que você segue e outros recursos que pode usar, como a seção. Em alta, o Marketplace e a Pesquisa. Usamos os dados que temos (por exemplo, sobre as conexões que você faz, as escolhas e configurações que seleciona e o que compartilha e faz dentro e fora de nossos Produtos) para personalizar sua experiência.

O artigo tem por proposição afirmar o fato de que, desta forma, negócios jurídicos entabulados entre empresas como o Facebook e o Google - principais players do mercado tecnológico - e Governos, com os seus usuários, acabam constituindo verdadeiras delegações consentidas e autorizadas a aqueles, que por sua vez acabam de obter autorização legal para usar algoritmos para impor suas vontades. O problema disto advém do fato de que, sujeitando o usuário à incidência de ferramentas computacionais tais como o da mineração de dados (Data Mining) e de técnicas de neuromarketing, acabam as empresas e os Governos constituindo nos algoritmos, verdadeiros empurrões e cutucadas (nudges), com o claro propósito de substituir a vontade Humana, e desta forma arquitetar escolhas ou ingerir tomadas de decisões que, influenciando no comportamento Humano, acabam não sendo benéficas e salutares, justamente porque a referida substituição da vontade tem um propósito nefasto: conformar os interesses exclusivos do lucro por intermédio da produção incessante de dados que sustenta o modelo de mineração de dados que baseia os negócios das empresas que

54 HARARI, Yuval Noah. Homo Deus: uma breve história do amanhã. p.370.

55 FACEBOOK. Termos de Uso e Serviço. Disponível em: https://pt-br.facebook.com/terms. Acesso em 10 dez. 2020. 
operam as redes sociais. É necessário ainda chamar a atenção para o fato de o programador do algoritmo estar imbuído de uma não neutralidade. Neste caso, o que impediria que o encadeamento de etapas a ser executado de forma automática pelo computador não estivesse eivado de uma má intenção, visando dolosamente induzir o usuário a escolhas equivocadas e a caminhos perigosos, influenciando decisivamente seu comportamento?

Ainda, é possível indagar a respeito da possibilidade de erro do algoritmo em sua tomada de decisão: se por acaso uma determinada inteligência artificial tomar uma decisão equivocada (porque sujeita a erros e equívocos) e com isto vier a prejudicar o usuário e terceiros, quem será responsabilizado por isto?

Quem ficará obrigado a indenizar os prejuízos decorrentes de uma má escolha ou decisão, pelo computador, se o algoritmo executa a tarefa de forma sozinha, automática e o que é mais interessante, na era dos "robôs", aprendendo sozinho e continuamente (machine learning e deep learning), sem interferência do Humano na consecução de suas atividades?

Outros questionamentos surgem: haveria a possibilidade de se responsabilizar individualizadamente o "robô", inteligente e autônomo que é em sua tomada de decisão, pelo seu erro? E se a decisão tomada pelo algoritmo gerar uma consequência que é punida do ponto de vista criminal, é possível se falar em reclusão ou detenção da inteligência artificial? Se admitida esta hipótese, como implementar e executar a pena? Logo, seria possível atribuir-se personalidade própria ao "robô" ou dotá-lo de uma vontade informática?

O sociólogo John Casti acredita na ocorrência da singularidade ${ }^{56}$ dos "robôs". E ele afirma:

O aumento da complexidade no mundo das máquinas está rapidamente ultrapassando o lado humano da equação. Ao contrário de algumas sobrecargas de complexidade a que me referi anteriormente, como um ataque de PEM ou o colapso da Internet, a singularidade é um evento $X$ que levará décadas, não minutos ou segundos, para acontecer. Entretanto, seus efeitos serão dramáticos e irreversíveis, expulsando os humanos do centro do palco do grande drama evolutivo da vida neste planeta ${ }^{57}$.

Denota-se, neste contexto da Sociedade de Algoritmos, que os primeiros passos rumo à singularidade da tecnologia já foram dados. Não só porque a falta de literacia digital por parte dos usuários acabaram gerando consequências de enorme gravidade, mas também porque é fragrante

56 A singularidade pode ser entendida, nas palavras de John Casti, como sendo uma "inteligência trans-humana", ou computadores "conscientes" dotados de inteligência. Neste sentido, vide a obra do autor, denominada de $\mathbf{O}$ Colapso de Tudo.

57 CASTI, John. O Colapso de Tudo. Rio de Janeiro: Editora Intrínseca, 2012. Versão do Kindle. Importa esclarecer que a versão da obra utilizada no artigo é a do leitor Kindle, da Amazon. É que este tipo de leitor de conteúdo não apresenta a opção de visualizar as páginas, mas apenas a posição em que ele se encontra. Esta posição, por sua vez, varia de acordo com o dispositivo em que o livro é aberto e da configuração do tamanho da letra e da página, o que, por evidente, altera o número da posição em que a citação se encontra, que passa a ser, portanto, não fixa. Ao mesmo tempo, a NBR 6023/2018 é absolutamente omissa no trato da questão, lamentavelmente deixando de abordar e transcorrer in albis a modernidade, em que o suporte papel sofre desmaterialização e os livros passam a ser cada vez mais online e interativos. 
o protagonismo da atuação dos produtos e serviços tecnológicos mais utilizados globalmente: a Sociedade de Algoritmos está absolutamente imersa e influenciada pelo contexto da tomada de decisão oriunda das programações informáticas automatizadas.

\section{CONSIDERAÇÕES FINAIS}

A constatação é a de que a errada forma pela qual o usuário se comporta em redes sociais é determinante para a sua exposição a riscos demasiadamente perigosos e desnecessários e criando, com isto, inúmeras consequências desagradáveis, com graves prejuízos de ordem financeira e aos direitos de personalidade. Ocorre que o processo de tomada de decisão do usuário diante dos aplicativos e das redes sociais está todo eivado de atitudes disfuncionais que são corroborados e incentivados em grande parte pelos algoritmos computacionais. Isto serve a explicar, então, porque há tantos maus comportamentos mesmo que se trate de pessoas consideradas dentro da normalidade, ou seja, que não estão com suas faculdades mentais atingidas por patologias e que, por premissa, buscam adotar a cautela e a preservação como tônica para prolongar a vida e atingir a felicidade que almeja.

Afirma-se isto porque, por evidente, todo este processo de influência sobre a tomada de decisão não se dá de maneira consciente, até porque há a adoção, pelas empresas de tecnologia, de muitas técnicas de neuromarketing ${ }^{58}$, que aplicadas em conjunto com algoritmos, são eficazes em explorar mecanismos cerebrais inconscientes em torno da influência do comportamento.

É sabido que as redes sociais lucram com a comercialização dos dados pessoais e sensíveis dos seus usuários para aqueles que estão dispostos a pagar uma alta quantia para receber, de forma filtrada, catalogada e tabulada, os hábitos, as predileções, as preferências e os gostos pessoais de cada um que, ao adentrar ao Facebook, por exemplo, concorda (uma vez que aderiu aos Termos de Uso e Serviço) em ceder.

Esta trama ganha contornos ainda mais dramáticos na contemporaneidade, na medida em que se vive, portanto, a sociedade que depende dos algoritmos, e é justamente nela que vai se verificar um aumento exponencial dos riscos e graves consequências socioambientais as quais o usuário está sujeito. Ainda, é onde a ciência do Direito encontra enormes lacunas e dificuldades, não conseguindo dar soluções efetivas e imediatas à gama de celeumas causados pelo uso massivo de aplicações tecnológicas que relevam o usuário à categoria de hipervulnerabilizado.

Logo, no contexto da Sociedade de Algoritmos, pode-se afirmar que o processo de tomada de decisão não é livre, racional e muito menos equilibrado: pelo contrário, a preconizada relação comercial do tipo "ganha-ganha" (em que a qualidade do produto ou serviço tecnológico se faz aprimorar e acompanhar de uma maturidade e discernimento sustentável na forma de uso pelo usuário) deu lugar

58 O neuromarketing é ramo derivado da neurociência que, aplicado às técnicas de venda e comércio, potencializam o consumo compulsivo e não refletido. 
à um cruel paradoxo onde se constata que, quanto maior a escalabilidade ${ }^{59}$ das aplicações tecnológicas (trazendo assim mais possibilidades, interação, instantaneidade no acesso à informação, conforto, dinamicidade e eficiência), menor é benefício auferido pelo usuário e maior o aumento dos seus riscos e consequentemente, da gama de problemas a que ele está sujeito a enfrentar.

Urge, dos operadores e cientista do Direito, uma postura atenta e crítica, pois somente se poderá atender Constituição da República do Brasil, que preconiza a construção de uma sociedade justa, livre e solidária (art. $\left.3^{\circ}, 1\right)$, através da promoção da liberdade de determinação (ou autodeterminação), que é condição sine qua non da promoção e garantia da cidadania e principalmente da dignidade da pessoa humana, que também é fundamental e deve ser preconizada e buscada sempre como garantia de sustentabilidade no ambiente digital e virtual.

\section{REFERÊNCIAS DAS FONTES CITADAS}

ABREU, Moises. Qual a importância de algoritmos na programação? Portal Acadtec. Disponível em: https:// www.acadtec.com.br/blog/desenvolvimento-backend/qual-a-importancia-de-algoritmos-na-programacao. Acesso em 10 dez. 2020.

ÂNGELO, Kedson. A história da criação do WhatsApp. Disponível em em: https://www.linkedin.com/pulse/ hist\%C3\%B3ria-da-cria\%C3\%A7\%C3\%A3o-do-whatsapp-kedson-angelo. Acesso em 10 dez. 2020.

BARABASI, Albert-Lászlo. Linked: a nova ciência dos networks. São Paulo: Leopardo Editora, 2009.

BHAGAT, Smriti; BURKE, Moira; DIUK, Carlos; FILIZ, Ismail Onur. Three and a half degrees of separation. Facebook Research. Disponível em: https://research.fb.com/three-and-a-half-degrees-of-separation/. Acesso em 10 dez. 2020.

BRASIL. [Constituição (1988)]. Constituição da República Federativa do Brasil de 1988. Brasília, DF: Disponível em: http://www.planalto.gov.br/ccivil_03/constituicao/constituicaocompilado.htm. Acesso em 10 dez. 2020.

BRASIL. [Lei 13.708 (2018)]. Lei de proteção de dados. Brasília, DF: Presidência da República [2018]. Disponível em: http://www.planalto.gov.br/ccivil_03/_Ato2015-2018/2018/Lei/L13709.htm. Acesso em 10 dez. 2020.

BRASIL. [Lei 13.718 (2018)]. Lei 13.718/2018. Brasília, DF: Presidência da República, [2018]. Disponível em: http://www.planalto.gov.br/ccivil_03/_Ato2015-2018/2018/Lei/L13718.htm. Acesso em 10 dez. 2020.

CASTELLS, Manuel. A galáxia da Internet, reflexões sobre a Internet, os negócios e a sociedade. Zahar, 2003.

CASTELLS, Manuel. A sociedade em rede. A era da informação: economia, sociedade e cultura. v.1.São Paulo: Paz e Terra, 1999.

CASTI, John. O Colapso de Tudo. Rio de Janeiro: Editora Intrínseca, 2012. Versão do Kindle.

CORMEN, Thomas H. Desmistificando algoritmos. $1^{\text {a }}$ ed. Rio de Janeiro: Elsevier, 2014.

EUROPE UNION GENERAL DATA PROTECTION REGULATION. Disponível em: https://eugdpr.org/. Acesso em 10 dez. 2020.

59 Escalabilidade ou escalonamento consubstancia-se na capacidade da nuvem computacional crescer de forma praticamente infinita, passando ao usuário/consumidor a sensação ou ilusão de capacidade infindável de armazenamentos, aplicações e recursos, na medida em que o pool de serviços pode ser livremente ampliado ou manejado conforme a demanda incide sobre a nuvem com o passar do tempo. 
FACEBOOK. Termos de Uso e Serviço. Disponível em: https://pt-br.facebook.com/terms. Acesso em 10 dez. 2020

FREITAS, Cinthia Obladen de Almendra. Redes sociais: sociedade tecnológica e inclusão digital. In: Marcos

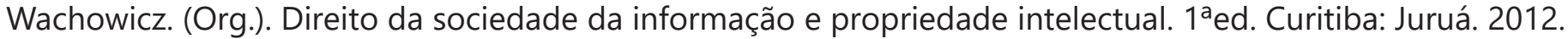

HARARI, Yuval Noah. Homo Deus: uma breve história do amanhã. $1^{a}$ ed. São Paulo: Companhia das Letras, 2016.

IBGE. Pesquisa nacional por amostra de domicílios - PNAD contínua. Ano 2018. Disponível em: https:// ftp.ibge.gov.br/Trabalho_e_Rendimento/Pesquisa_Nacional_por_Amostra_de_Domicilios_continua/Anual/ Acesso_Internet_Televisao_e_Posse_Telefone_Movel_2018/Analise_dos_resultados_TIC_2018.pdf. Acesso em 10 dez.2020.

INTERNET WORLD STATS. Internet usage statistics. Disponível em: https://www.internetworldstats.com/stats. htm. Acesso em 10 dez. 2020.

JORNAL THE TELEGRAPH. Who owns Snapchat and when was it created?. Disponível em: https://www. telegraph.co.uk/technology/0/owns-snapchat-created/. Acesso em 10 dez. 2020.

PIERRO, Bruno de. O Mundo mediado por algoritmos. São Paulo: Revista Pesquisa Fapesp. ed. 266, abr. 2018. Disponível em: http://revistapesquisa.fapesp.br/2018/04/19/o-mundo-mediado-por-algoritmos/. Acesso em 10 dez. 2020.

PLAYSTORE. Disponível em: https://play.google.com/store. Acesso em 10 dez. 2020.

PORTAL STATISTA. Disponível em: https://www.statista.com/statistics/545967/snapchat-app-dau/. Acesso em 10 dez. 2020.

PORTAL TECHTUDO. WhatsApp bate marca de 1,5 bilhão de usuários ativos. Disponível em: https://www. techtudo.com.br/noticias/2018/02/whatsapp-bate-15-bilhao-de-usuarios-ativos.ghtml. Acesso em $10 \mathrm{dez}$. 2020.

RECUERO, Raquel da Cunha. Redes sociais na internet: considerações iniciais. Porto Alegre: Editora Compós, v. 2, 2005. Disponível em: http://www.ufrgs.br/limc/PDFs/redes_sociais.pdf. Acesso em 10 dez. 2020.

SANTANA JUNIOR, Edemilson Cruz. A digitalização do mercado de capitais no Brasil: tendências recentes. Instituto de Pesquisa Econômica Aplicada. Brasília: Rio de Janeiro, 2018. Disponível em: http://repositorio.ipea. gov.br/bitstream/11058/8280/1/TD_2370.PDF. Acesso em Acesso em 10 dez. 2020.

SANTOS, Erick Muzart Fonseca dos. A revolução dos algoritmos. Portal Inova TCU. Disponível em: https:// portal.tcu.gov.br/inovatcu/noticias/a-revolucao-dos-algoritmos.htm. Acesso em 10 dez. 2020.

SCHWAB, Klaus. A quarta revolução industrial. São Paulo: Edipro, 2016.

THE GUARDIAN. How algorithms rule the world. Disponível em: https://www.theguardian.com/science/2013/ jul/01/how-algorithms-rule-world-nsa. Acesso em 10 dez. 2020.

UNITED NATIONS. International Telecommunication Union. Internet users statistics by region and country 2005-2019. Disponível em: https://www.itu.int/en/ITU-D/Statistics/Pages/stat/default.aspx. Acesso em 10 dez.2020.

Recebido em: 21/06/2020

Aprovado em: 03/12/2020

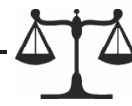

